\title{
Non-expression of a common mutation in the 21-hydroxylase gene: implications for prenatal diagnosis and carrier testing
}

\author{
G Rumsby, A F Massoud, C Avey, C G D Brook
}

\begin{abstract}
Mutation analysis in the family of a child with 21-hydroxylase deficiency showed that the father and affected child were homozygous for a mutation, A/C655G, believed to activate a cryptic splice site in intron 2 of the 21-hydroxylase gene. The father, who was clinically asymptomatic, showed no biochemical evidence of disease. These results create problems for the management of future pregnancies in such families and for the interpretation of the risk associated with carrier status for this mutation.

(F Med Genet 1996;33:798-799)
\end{abstract}

Key words: 21-hydroxylase; mutation; non-expression.

Deficiency of the steroid 21-hydroxylase (CYP21) enzyme is the most frequent cause of congenital adrenal hyperplasia (CAH). It is characterised by glucocorticoid and mineralocorticoid insufficiency leading to salt loss in the neonatal period, and increased synthesis of adrenal androgens leading to virilisation of the female fetus in utero and to precocious puberty in undiagnosed males.

The gene, CYP21, is located on chromosome $6 \mathrm{p}$ within the HLA class III region. More than $95 \%$ of mutations are the result of either recombination with a pseudogene some 30 kilobases (kb) upstream leading to gross deletions at the locus or smaller gene conversions in which part of the CYP21 sequence is replaced by that of the pseudogene, CYP21P. The mutations are so frequent that they can be used as part of a diagnostic repertoire for prenatal diagnosis and carrier testing for the disease. ${ }^{1-3}$

One mutation in the second intron occurs at a polymorphic site such that either adenosine or cytosine is replaced by guanine at nucleotide 655 and is believed to influence the activation of a cryptic splice site some 19 nucleotides upstream of exon $3 .^{4}$ The mutation is relatively common, occurring on approximately $34 \%$ of alleles in our series of 90 patients (G Rumsby, unpublished data) and from 17 to $32 \%$ in other published reports. ${ }^{5}$ The mutation profile of a family presenting for prenatal diagnosis of $\mathrm{CAH}$ showed that one of the parents was homozygous for this mutation. Here we report the investigation of this family and discuss the implications for prenatal diagnosis of this disease.
The index case is a girl of Arab extraction and the product of a consanguineous marriage. She was born at 36 weeks' gestation following a normal pregnancy and delivery and was noted to have ambiguous genitalia (large phallus, fused labioscrotal folds, and 46, XX karyotype). Investigations in the United Arab Emirates confirmed the diagnosis of 21-hydroxylase deficiency (details not available). The parents were advised to rear the baby as a girl. She was started on steroid replacement therapy with plans for reconstructive surgery at a later date. However, the parents did not accept the diagnosis and decided to rear the child as a boy. The child was referred to our centre for a second opinion at the age of 13 months. She was well controlled on hydrocortisone $5 \mathrm{mg}$ twice daily $\left(22 \mathrm{mg} / \mathrm{m}^{2} /\right.$ day $)$ and fluodrocortisone 75 $\mu \mathrm{g}$ once daily $\left(167 \mu \mathrm{g} / \mathrm{m}^{2} /\right.$ day $)$. Examination of her genitalia showed a large clitoris, an empty scrotum, and a urogenital sinus. The diagnosis of CYP21 deficiency was confirmed on urinary steroid profile (high excretion rates of 17hydroxyprogesterone metabolites). Pelvic ultrasound scan showed a normal prepubertal uterus. Sinography showed a blind ended pouch $3 \mathrm{~cm}$ long from the base of the phallus. Blood for DNA studies was collected from the child and her parents. Cliteroplasty and vaginal reconstruction were performed at our centre.

The parents were heterozygous for polymorphisms in $\mathrm{C}^{6}$ and $\mathrm{TNFa},{ }^{7}$ with one allele in common. The index case had inherited identical linked markers from each parent.

The A/C655G mutation in CYP21 was sought by amplification of genomic DNA in a $25 \mu$ l reaction mix containing $1.5 \mathrm{mmol} / 1$ $\mathrm{MgCl}_{2}, 1 \mu \mathrm{mol} / 1$ each primer (nts $707-725^{8}$ and 369-388), $200 \mu \mathrm{mol} / \mathrm{l}$ each dNTP, 50 $\mathrm{mmol} / 1 \mathrm{KCl}, 10 \mathrm{mmol} / \mathrm{l}$ Tris, $\mathrm{pH} 9.0,0.1 \%$ Triton X-100, and 0.25 units of Taq polymerase. Following an initial denaturation step, 35 cycles of 0.5 minutes at $62^{\circ} \mathrm{C}, 0.5$ minutes at $72^{\circ} \mathrm{C}$, and 0.5 minutes at $94^{\circ} \mathrm{C}$ were carried out. The PCR product was digested with $M$ woI to detect the presence of the $\mathrm{A} / \mathrm{C} 655 \mathrm{G}$ mutation and the T453C polymorphism.

Mutation analysis showed that the index case was homozygous for the splice mutation in intron 2 and the mother heterozygous for this mutation. The father, however, was found to be homozygous for the same mutation. Nonamplification of one paternal allele was excluded by amplification with an additional primer pair (nts 600-618 and 797-816) followed by digestion of the product with MwoI. 
Samples from subjects lacking either CYP21 or CYP21P were used as controls. ${ }^{9}$ Sequence analysis of two clones containing the paternal CYP21 intron 2 confirmed the presence of the A/C655G mutation and the T453C polymorphism in addition to a $\mathrm{C}$ to $\mathrm{A}$ change at nucleotide 419 . In view of the father's genotype the following biochemical investigations were performed: $\mathrm{Na}^{+} 141 \mathrm{mmol} / \mathrm{l}, \mathrm{K}^{+} 4.4 \mathrm{mmol} / \mathrm{l}$, urea $7 \mathrm{mmol} / 1$, serum cortisol $381 \mathrm{nmol} / \mathrm{l}$, plasma aldosterone (recumbent) $312 \mathrm{pmol} / 1$ (100$500)$, plasma renin activity (PRA) (recumbent) $3.25 \mathrm{pmol} / \mathrm{h} / \mathrm{ml}$ (1.14-2.65). A urine steroid profile showed raised pregnanetriol (1560 $\mu \mathrm{g} /$ day; normal for adult males:110-520). Following synacthen stimulation $(250 \mu \mathrm{g}$ intravenous bolus) serum 17-hydroxyprogesterone rose from a basal level of 2.9 $\mathrm{nmol} / 1$ to $8.1 \mathrm{nmol} / 1$ at 60 minutes (normal $<20 \mathrm{nmol} / \mathrm{l}$ ). These investigations excluded a diagnosis of $\mathrm{CAH}$ despite his homozygous genotype.

Mutation analysis is the most accurate form of genetic diagnosis as it detects the actual sequence change causing the disease and is therefore less susceptible to error through recombination. However, here we describe a family in whom one of the parents is homozygous for a known deleterious mutation but clinically asymptomatic and biochemically normal except for a slightly raised urinary pregnanetriol and mildly raised PRA. Such a situation has been recently described ${ }^{10}$ but no satisfactory explanation was presented.

The association of the A/C $655 \mathrm{G}$ mutation with activation of a cryptic splice site has been described in vitro ${ }^{41}$ and in vivo (C Avey, G Rumsby, G Conway, manuscript in preparation). Mutations which affect splicing are known to be leaky, ${ }^{12}$ the cell making a certain amount of normally spliced mRNA, and one could therefore hypothesise that the mutation is variably expressed. Such an explanation may help in part to account for the inexact relation between genotype and phenotype in CYP21 deficiency. ${ }^{13}$ As no additional homozygotes were available for study in this particular family, it is not possible to know whether such variation can occur within a family. A second possibility is that the $\mathrm{A} / \mathrm{C} 655 \mathrm{G}$ mutation may occur in the presence of an additional sequence change in either the intron or neighbouring exon, which negates the influence of the mutation on the cryptic splice site. The sequence data obtained in the present study did not, however, identify any additional pathological sequence changes in this region. This subject was, however, homozygous for five polymorphisms in the intron 2 /exon 3 region and it was therefore not possible to claim with certainty that both alleles were sequenced. Lastly, $655 \mathrm{G}$ may simply be in association with another mutation, although this proposal is unlikely in view of the expression studies discussed above.

Family studies on patients with CYP21 deficiency have identified subjects who had not presented clinically although were found to have the disease on biochemical testing (cryptic $\mathrm{CAH}$ ). Genetic analysis as described in this manuscript has now also identified people homozygous for disease mutations but who are clinically asymptomatic and show only minor biochemical abnormalities. The problem for the doctor is the management of the family. It would seem justified to test all homozygotes for the mutation for their response to synacthen stimulation to exclude cryptic CAH. If there is no response or one indicating carrier status alone, can prenatal diagnosis be offered using linkage analysis to differentiate between the two alleles? The alternative is to offer prenatal treatment of the pregnancy with dexamethasone to term in the case of a female homozygous for the mutation. Biochemical testing after birth in both males and females will then confirm their disease status.

It is simply not known at this time whether the asymptomatic homozygotes for the splice site mutation will go on to develop the disease later in life. Until more is known about what makes this mutation active, it poses major difficulties for genetic counselling of these families and carriers of such a mutation.

1 Rumsby G, Honour JW, Rodeck C. Prenatal diagnosis of congenital adrenal hyperplasia by direct detection of mutations in the steroid 21-hydroxylase gene. Clin Endocrinol 1993;38:421-5.

2 Speiser PW, White PC, Dupont J, Zhu D, Mercado AB, New MI. Prenatal diagnosis of congenital adrenal hyperplasia due to 21-hydroxylase deficiency by allelehyperplasia due to 21-hydroxylase deficiency by allelespecific hybridizat

3 Weddell A, Thillen A, Ritzen EM, Stengler B, Luthman H. Mutational spectrum of the steroid 21-hydroxylase gene in Sweden: implications for genetic diagnosis and association with disease manifestation. I Clin Endocrinol Metab 1994; 78:1145-52.

4 Higashi $Y$, Tanae A, Inoue H, Hiromasa T, Fujii-Kuriyama Y. Aberrant splicing and missense mutations causing 21-hydroxylase [P-450(C21)] deficiency in humans: possible gene conversion products. Proc Natl Acad Sci USA 1988;85:7486-90.

5 Wilson RC, Wei JQ, Cheng KC, Mercado AB, New MI. Rapid deoxyribonucleic acid analysis by allele specific polymerase chain reaction for detection of mutations in the steroid 21-hydroxylase gene. $\mathcal{F}$ Clin Endocrinol Metab 1995;80:1635-40.

6 Schneider PM, Carroll MC, Alper CA, et al. Polymorphism of the human complement $\mathrm{C} 4$ and steroid 21-hydroxylase genes. $\mathcal{F}$ Clin Invest 1986;78:650-7.

7 Udalova IA, Nedospasov SA, Webb GC, Chaplin DD, Turetskaya RL. Highly informative typing of the human TNF locus using six adjacent polymorphic markers. Genomics 1993;16:180-6.

8 Higashi $\mathrm{Y}$, Yoshioka $\mathrm{H}$, Yamane $\mathrm{M}$, Gotoh O, FujiiKuriyama Y. Complete nucleotide sequence of two steroid 21-hydroxylase genes tandemly arranged in human chromosome: a pseudogene and a genuine gene. Proc Natl Acad Sci USA 1986;83:2841-5.

9 White PC, New MI, Dupont B. Structure of human steroid 21-hydroxylase genes. Proc Natl Acad Sci USA 1986; 83:5111-15.

10 Schulze E, Scharer G, Rogatzki A, et al. Divergence between genotype and phenotype in relatives of patients with the genotype and phenotype in relatives of patients with the
intron 2 mutation of steroid 21 -hydroxylase. Endocrine Res intron 2 mutation

11 Owerbach D, Ballard AL, Draznin MB. Salt-wasting congenital adrenal hyperplasia: detection and characterization of mutations in the steroid 21-hydroxylase gene, CYP21, using the polymerase chain reaction. $\mathcal{f}$ Clin Endocrinol Metab 1992;74:553-8.

12 Moskowitz SM, Tieu PT, Neufeld EF. Mutation in Scheie syndrome (MPS IS): a G A transition creates new splice site in intron 5 of one IDUA allele. Hum Mutat 1993;2:141-4.

13 Wilson RC, Mercado AB, Cheng KC, New MI. Steroid 21-hydroxylase deficiency:genotype may not predict phenotype. $\mathcal{f}$ Clin Endocrinol Metab 1995;80:2322-9. 